\title{
Penetration Estimation of GMA Backing Welding Based on Weld Pool Geometry Parameters
}

\author{
Junfen Huang, Long Xue*, Jiqiang Huang, Yong Zou and Ke Ma
}

\begin{abstract}
Penetration estimation is a prerequisite of the automation of backing welding based on vision sensing technology. However, the arc interference in welding process leads to the difficulties of extracting the weld pool characteristic information, which brings great challenges to the penetration estimation. At present, most researches focus on the extraction of weld pool geometry parameters, and the visual sensing systems are complex in structure and complicated in the image processing algorithms. The research of penetration estimation based on weld pool geometry parameters is still in the exploratory stage. The purpose of this paper is to research the relationship between the weld pool geometry parameters and the penetration during backing welding and to estimate penetration using the weld pool geometry parameters. A passive vision sensing test system for gas metal arc (GMA) backing welding was established. An image processing algorithm was developed to extract the weld pool geometry parameters, namely, the area, maximum width and length, half-length, length-width ratio and advancing contact angle (simplified as AWP, MWWP, MLWP, HLWP, LWR and ACA, respectively). The corresponding relationships between the weld pool geometry parameters and the penetration state were explored by analysing their changes with the welding current and speed. The distribution of the weld pool geometry parameters corresponding to penetration was determined. When the AWP of the weld pool is within a certain range and the values of LWR and ACA are close to their maximum and minimum respectively, the penetration is in good condition. A mathematical model with the weld pool geometry parameters as independent variables and the back-bead width (the indicator of the penetration state) as a dependent variable was established based on multivariable linear regression analysis, and relevant statistical tests were carried out. Multivariable linear regression equations for the weld pool geometry parameters and the back-bead width were deduced according to the variations in the current and speed, and the equations can be used to estimate the penetration of backing welding. The study provides a solution to penetration estimation of GMA backing welding based on automatic vision sensing.
\end{abstract}

Keywords: Welding automation, Passive vision sensing, Weld pool geometry parameters, Penetration state, Mathematical model

\section{Introduction}

With the development of industrial automation, intelligent and digital technology, automatic welding technology is now widely used in the petrochemical industry [1], construction machinery [2], shipbuilding [3], marine engineering [4], aerospace [5], rail transportation and

\footnotetext{
${ }^{*}$ Correspondence: xuelong@bipt.edu.cn

Opto-Mechatronic Equipment Technology Beijing Area Major Laboratory, Beijing Institute of Petrochemical Technology, Beijing 102617, China
}

other industries. The key technology of welding automation, such as mechanical technology [6], sensor technology $[7,8]$ and automatic control technology [9], has become a hot research topic. Weld quality and automatic welding performance are followed with interest.

Quality problems, such as partial penetration or excessive penetration, are often encountered in the backing welding process, and manual backing welding by skilled welders is still required to ensure the welding quality of butt welding [10], which seriously restricts the 
popularization and promotion of automatic welding. Automatic extraction of penetration information is a prerequisite of backing welding automation, and related research work mainly on arc sound-, temperature field-, oscillation frequency-, ultrasonic-, infrared- and visionbased sensing methods has been carried out. The vision sensing method has attracted extensive attention globally because abundant weld pool information can be obtained with little effect on the welding process $[11,12]$.

Vision sensing technology is usually divided into two modes: active vision and passive vision. For active vision, the weld pool images are acquired with specific light sources, such as lasers [13]; for passive vision, the weld pool images are acquired with arc and reflection of weld pool on arc as light sources. Compared with active vision, the passive vision method is more consistent with the vision system of welders, and the image acquisition device is relatively simple, providing more flexibility in the welding field [14].

Many studies on active vision sensing technology have been carried out. Kovacevic et al. [15] proposed a sensing mechanism to detect the free weld pool surface. The stripes reflected from the weld pool were detected, and the reflection pattern and pool boundary were related to the weld penetration. Researchers at the University of Kentucky carried out a series of studies on monitoring the weld pool surface [16]. A laser pattern was projected on the weld pool surface, and the laser reflected from the specular surface was intercepted at a distance from the arc [17]. The reflection law has been used to analytically calculate the weld pool surface in real time [18]. Related research has also been carried out at the Lanzhou University of Technology, where Zhang et al. [19] proposed a laser vision method using a low-power fractional laser to cover the entire pool surface and a high-speed camera to capture the laser image reflected from the molten metal surface. The geometry feature parameters of the three-dimensional free surface of the weld pool are obtained off-line and are in good agreement with the measured values. However, to estimate the penetration state from any top-side measurements, including the weld pool surface, models are needed. Empirical modelling has been studied to certain extent [20,21]. Unfortunately, for the most promising top-side measurement (3D weld pool surface), success in empirical modelling has been limited.

Meanwhile, studies on extraction of the weld pool information by passive vision methods have been performed in recent years [22]. Fan [23] designed a multilight-source vision-based sensing subsystem to capture weld pool images from the top-back, top-front and back directions simultaneously according to the requirements for an aluminium alloy gas tungsten arc welding (GTAW) control system. A narrowband composite filter system was developed, and an image acquisition scheme for the weld pool was determined. Clear and stable images of the weld pool were obtained, and an image processing algorithm was developed to extract the width and halflength of the weld pool. Shen et al. [24] proposed a twowindow passive vision sensing technique for tungsten argon arc welding of an aluminium alloy, and geometry parameters such as the weld pool width and weld gap can be clearly observed. The geometric characteristics of the image can be extracted stably through image processing technology and can be used as the diagnostic information for the welding quality and seam tracking technology. Wang et al. [25] determined the acquisition time of the CCD camera and accurately found the exposure time of the CCD camera at the moment of short-circuiting transfer for visual detection of the weld pool in the process of gas metal arc (GMA) short-circuiting welding. An image acquisition method with a small angle at the front and a large angle at the back was proposed, and an image processing algorithm was designed to extract the edge of the weld pool. Gao et al. [26] designed a visual sensor composed of an ordinary CCD camera and a filter lens, and weld pool images were observed from the front of the specimen. The brightness of the images was adjusted by software according to the current in the welding process, and a clear TIG welding pool image was obtained. The geometry parameters of the weld pool were detected by the image processing algorithm. Liu et al. [27] presented a real-time passive machine vision system for weld pool sensing in robotic arc welding and proposed a detection algorithm to extract the geometrical profile of the weld pool. Since the weld pool is dynamic and its image is affected by the arc, reliable extraction of geometry parameters is a major research focus [28]. Some researchers proposed 3D weld pool reconstruction algorithms based on the shape-from-shading (SFS) method [29-31]. Zhao et al. [30] used the SFS algorithm to reconstruct the surface from one single weld pool image. Twodimensional shape parameters were extracted from a 2D image processing algorithm. Finally, an SFS algorithm was implemented on a single weld pool image to recover the surface height. However, SFS algorithms are usually complex and are thus used for off-line reconstruction of the 3D weld pool surface.

Although studies on the extraction of shape parameters of the weld pool have been performed, characterization of penetration using the weld pool geometry parameters is still at the exploratory stage. There are no proper measurement or estimation methods for determining the penetration state from the geometric parameters of the weld pool surface. Therefore, research on the extraction of the geometric parameters of the gas metal arc 
welding (GMAW) weld pool was conducted with weld pool images captured by a passive visual sensing method, and the relationships between geometric parameters and the penetration state at different welding currents and speeds were analysed. Then, equations to predict the penetration state from the geometric parameters were determined based on statistical analysis.

\section{Test System and Welding Parameters}

A test system for GMA backing welding was established and consisted of two parts: a welding test platform and an image acquisition system. The welding test platform comprises a welding power supply, a welding torch, a welding control unit and a 3D mobile platform, and the image acquisition system is mainly composed of a computer, two industrial CMOS cameras with narrowband composite filters, and a high-speed network card, as shown in Figure 1.

In the welding test platform, the welding power supply (AoTai Pulse MIG-500) was used for welding, the welding control unit with PLC as the core was used to adjust the welding parameters and control the welding process, and the $3 \mathrm{D}$ mobile platform was used for position adjustment and movement of the workpiece. The V-groove butt backing welding procedure was adopted in the tests, and the root face of the V-groove was $1 \mathrm{~mm}$. The inclination angle between the welding torch and the workpiece surface was $75^{\circ}$, the diameter of welding wire was $1.2 \mathrm{~mm}$, and the electrode extension was within the range from $12 \mathrm{~mm}$ to $18 \mathrm{~mm}$. The material for testing was a Q235 steel plate with a size of $260 \mathrm{~mm} \times 90 \mathrm{~mm} \times 12 \mathrm{~mm}$, and $\mathrm{CO}_{2}$ was used as the shielding gas.

Two Mako G-192B/C (produced by Allied Vision, Germany) cameras were utilized for image acquisition of the front and back of the weld pool, and the camera was an industrial Gigabit Ethernet camera with a high

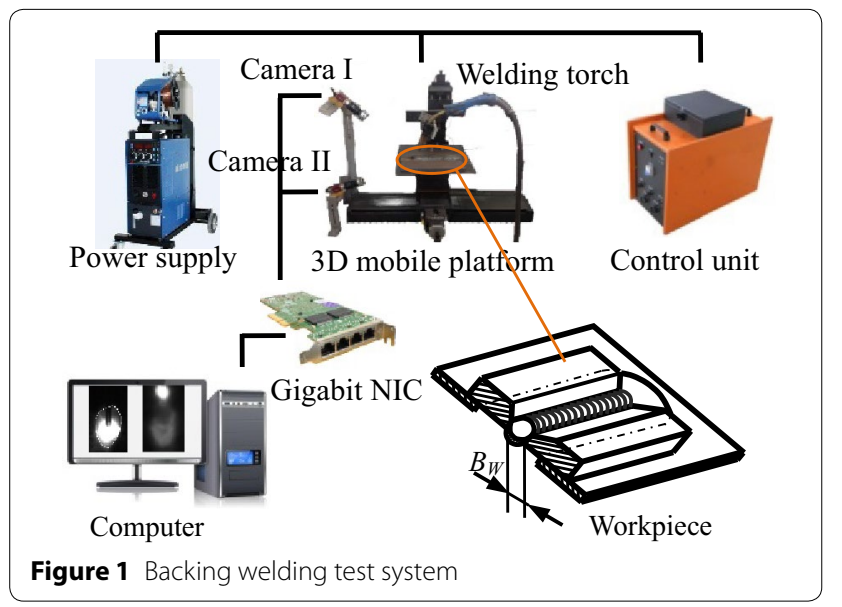

frame rate of $60 \mathrm{fps}$. The resolution of the camera was $1600 \times 1200$, and its cell size was $4.5 \mu \mathrm{m}$. The camera was equipped with a Computar M7528-MP lens, which had a focal length of $75 \mathrm{~mm}$. Image data transmission was achieved by an Intel PCI-E $4 \times$ Gigabit Ethernet card, which can meet the transmission speed requirement. Since the arc and welding spatter caused strong interference with the weld pool image in the GMA welding process, a narrowband filter with an optical attenuation film was installed at the front of the lens. A filter with a central wavelength of $650 \mathrm{~nm}$ and a bandwidth of $\pm 10 \mathrm{~nm}$ was selected, and according to image acquisition tests, the light transmittance of the optical attenuation film was $10 \%$.

Automatic GMA backing welding tests were conducted using the test system. The welding torch and CMOS cameras for image acquisition remained stationary, and the workpiece was moved at a uniform speed during the welding process. The relationship between the weld pool geometry parameters and the penetration state was studied at different welding currents and speeds, and the welding parameters adopted are shown in Table 1.

\section{Test Results and Analysis}

Image acquisition of the weld pool was carried out during the welding process, and the geometric characteristics were extracted by an image processing algorithm. The variation trends of geometry parameters with the welding current and speed were analysed, and the distribution of the geometry parameters corresponding to penetration was determined.

\subsection{Image Acquisition and Processing}

Image acquisition and processing were achieved using HALCON software, a set of standard machine vision algorithms developed by MVtec Company in Germany. This software has an extensive machine vision integrated development environment for rapid development of machine vision and image analysis applications.

Table 1 Welding parameters

\begin{tabular}{lllll}
\hline $\begin{array}{l}\text { Welding } \\
\text { current } \\
\boldsymbol{I}(\mathbf{A})\end{array}$ & $\begin{array}{l}\text { Welding } \\
\text { speed } \boldsymbol{v}(\mathbf{c m} / \\
\text { min) }\end{array}$ & $\begin{array}{l}\text { Diameter } \\
\text { of welding wire } \\
\boldsymbol{d}(\mathbf{m m})\end{array}$ & $\begin{array}{l}\text { Groove } \\
\text { angle } \boldsymbol{a}_{\mathbf{g}} \\
\left({ }^{\circ}\right)\end{array}$ & $\begin{array}{l}\text { Root } \\
\text { opening } \boldsymbol{b} \\
(\mathbf{m m})\end{array}$ \\
\hline 110 & 15 & & & \\
120 & 20 & & & \\
130 & 25 & 1.2 & & \\
140 & 30 & & & \\
150 & 35 & & & \\
160 & 40 & & & \\
\hline
\end{tabular}


To determine the relationship between each geometric parameter of the weld pool surface and its corresponding pixels in the image, camera calibration was carried out using HALCON software. The width of each pixel corresponded to $0.025 \mathrm{~mm}$, the length of each pixel corresponded to $0.0417 \mathrm{~mm}$.

Welding tests and image acquisition were carried out according to the test scheme. Weld pool images obtained at currents from $110 \mathrm{~A}$ to $160 \mathrm{~A}$ with a step size of $10 \mathrm{~A}$ and a welding speed of $20 \mathrm{~cm} / \mathrm{min}$ are shown in Figure 2 .

The weld pool geometry parameters are shown in Figure 3, where $W$ and $L$ represent the maximum width and length of the weld pool (MWWP and MLWP), $W=W_{1}+W_{2}$, and $L_{\mathrm{h}}$ is the half-length of the weld pool (HLWP). $\alpha$ is defined as the advancing contact angle

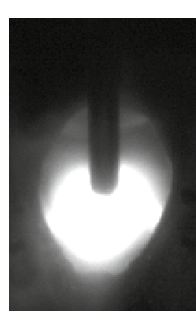

(a) $I=110 \mathrm{~A}$

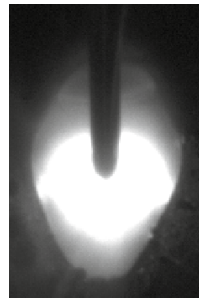

(d) $I=140 \mathrm{~A}$

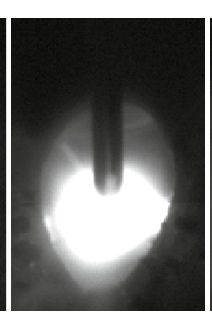

(b) $I=120 \mathrm{~A}$

(c) $I=130 \mathrm{~A}$

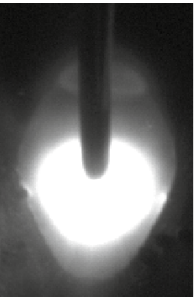

(e) $I=150 \mathrm{~A}$

(f) $I=160 \mathrm{~A}$

Figure 2 Weld pool images of GMAW at different currents

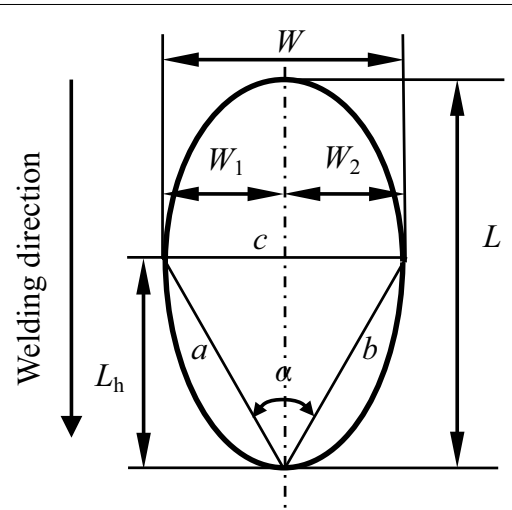

Figure 3 Weld pool geometry parameters
(ACA), and $a, b$, and $c$ indicate lines connecting the local extreme points of the weld pool profile. The area of the weld pool (AWP), length-width ratio (LWR), ACA, MLWP and MWWP are discussed in this paper. The AWP is calculated by counting all the pixels included in the profile of the weld pool, denoted $S$; the LWR of the weld pool is expressed by $R$, where $R=L / W$; and the ACA can be computed by Eq. (1):

$$
\alpha=\arccos \left[\left(a^{2}+b^{2}-c^{2}\right) / 2 a b\right],
$$

where

$$
\begin{aligned}
& a=\sqrt{L_{h}^{2}+W_{1}^{2}}, \\
& b=\sqrt{L_{h}^{2}+W_{2}^{2}} .
\end{aligned}
$$

An image processing algorithm was developed to extract the profile of the weld pool and calculate AWP, MLWP, MWWP, LWR and ACA. Observing the weld pool image shows that the arc region was superimposed on the weld pool region and that the greyscale of the arc was much larger than that of the weld pool. Therefore, the arc region was first recognized by binarization, and the region around the weld pool was divided into four parts centred on the arc region. Then, the weld pool in each part was obtained by binarization, and the four parts, combined with the arc region, constituted the whole weld pool region. The profile of the weld pool was extracted, and the geometric parameters AWP, MLWP, MWWP, LWR and ACA were calculated. The flow chart for image processing of the weld pool is shown in Figure 4. The extracted weld pool profiles at currents from $110 \mathrm{~A}$ to $160 \mathrm{~A}$ are shown in Figure 5.

\subsection{Relationship between Weld Pool Geometry Parameters and Penetration at Different Currents}

The welding parameters were as follows: the welding current was changed from 110 A to 160 A with a step size of $10 \mathrm{~A}$, the welding speed was $20 \mathrm{~cm} / \mathrm{min}$, the groove angle was $60^{\circ}$, and the groove gap was $1.6 \mathrm{~mm}$. The backs of welds are shown by Figure 6 . The penetration state is usually characterized by the back-bead width, and a backbead width between $2 \mathrm{~mm}$ and $3 \mathrm{~mm}$ indicates that complete penetration is achieved for the $\mathrm{V}$-groove workpieces used in the tests. It can be concluded that incomplete penetration of the weld root appears at a current of $100 \mathrm{~A}$ or $120 \mathrm{~A}$ (the back-bead width is less than $2 \mathrm{~mm}$ ), that the penetration is good at a current of $130 \mathrm{~A}$ or $140 \mathrm{~A}$, and that excessive penetration occurs when the welding current is set to $150 \mathrm{~A}$ or $160 \mathrm{~A}$ (the back-bead width is greater than $3 \mathrm{~mm}$ ). 


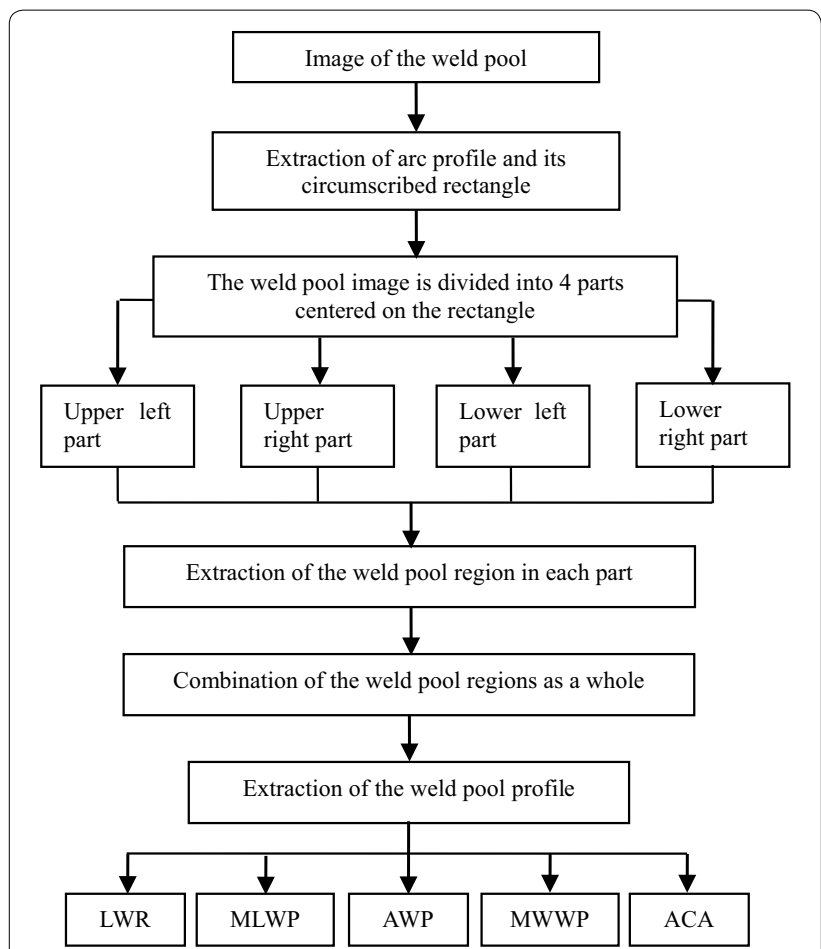

Figure 4 Flow chart for image processing of the weld pool

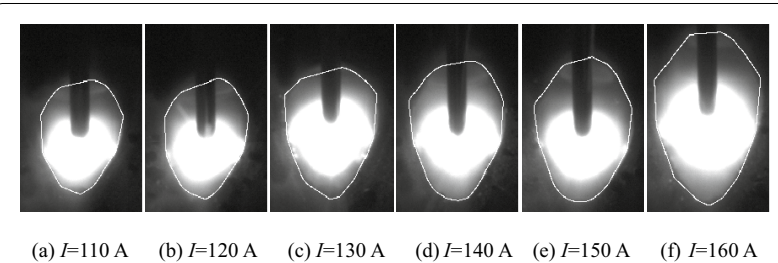

Figure 5 Weld pool profiles at different currents

The weld pool images were captured continuously during backing welding, and the geometric parameters AWP, MLWP, MWWP, HLWP, LWR and ACA were calculated.
To improve the reliability of the geometry parameters, the mean value of the same geometry parameter in more than 100 weld pool images was calculated to represent the weld pool geometry parameter under a set of different welding parameters. The geometry parameters AWP, LWR and ACA vary with the current as shown in Figure 7.

As seen from Figure 7, with the increase in welding current, the AWP keeps increasing, the LWR first increases and then decreases with a maximum value at the $140 \mathrm{~A}$ current, and the ACA has a variation trend opposite to the LWR. Complete penetration of the weld is achieved when the values of LWR and ACA are near their maximum and minimum respectively and the value of AWP is in a certain range.

The AWP is affected by the heat input to the weldment and the propagation velocity of the heat in the weldment. The greater the welding current is, the more heat is input into the weldment per unit time, which results in a higher temperature of the weldment and a greater temperature range above the melting point. Therefore, the AWP increases with the welding current, and the MLWP $(L)$ and MWWP $(W)$ also increase with the current at different slopes, as shown in Figure 8. On the other hand, the $\operatorname{HLWP}\left(L_{\mathrm{h}}\right)$ has a local maximum at $140 \mathrm{~A}$ in the process of increase. The variation trends of MLWP, MWWP and HLWP lead to the inflection points of the LWR and ACA observed in Figure 7.

\subsection{Relationship between Weld Pool Geometry Parameters and Penetration at Different Welding Speeds}

The backing welding tests were carried out while changing the welding speed from $15 \mathrm{~cm} / \mathrm{min}$ to $40 \mathrm{~cm} / \mathrm{min}$. The welding current was set to $140 \mathrm{~A}$, the groove angle was $60^{\circ}$, and the root opening was $1.6 \mathrm{~mm}$. The back of each weld is shown in Figure 9. It can be concluded that excessive penetration appears at a speed of $15 \mathrm{~cm} / \mathrm{min}$

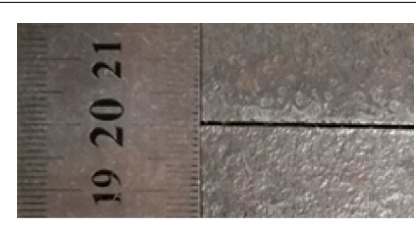

(a) $I=110 \mathrm{~A}$

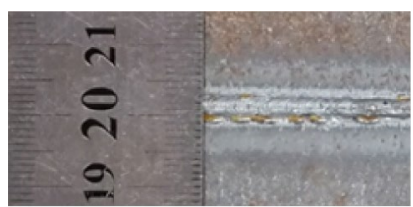

(d) $I=140 \mathrm{~A}$

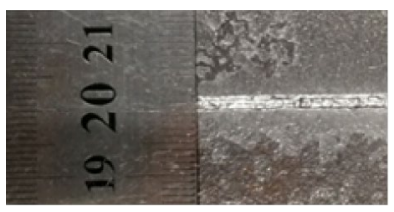

(b) $I=120 \mathrm{~A}$

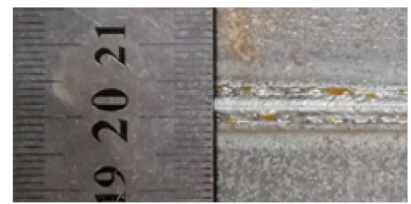

(e) $I=150 \mathrm{~A}$

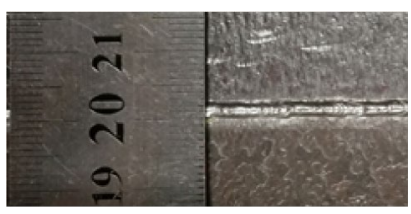

(c) $I=130 \mathrm{~A}$

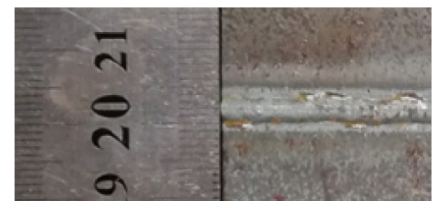

(f) $I=160 \mathrm{~A}$

Figure 6 Back of welds at different currents 


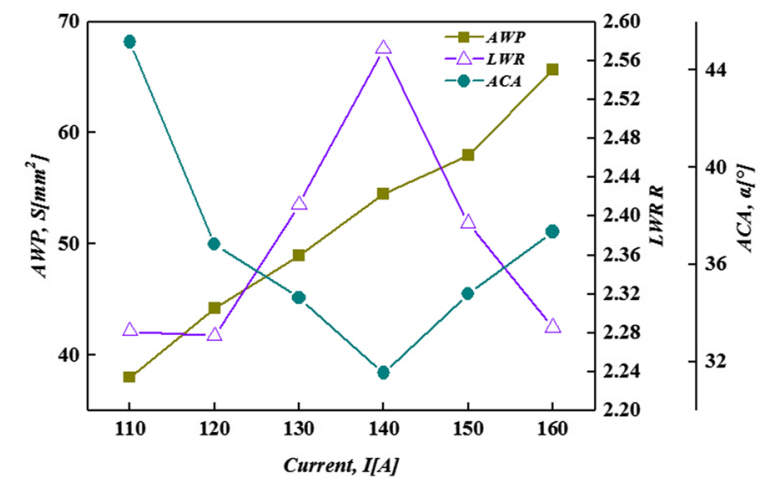

Figure 7 Variation trends of AWP, LWR and ACA with the current

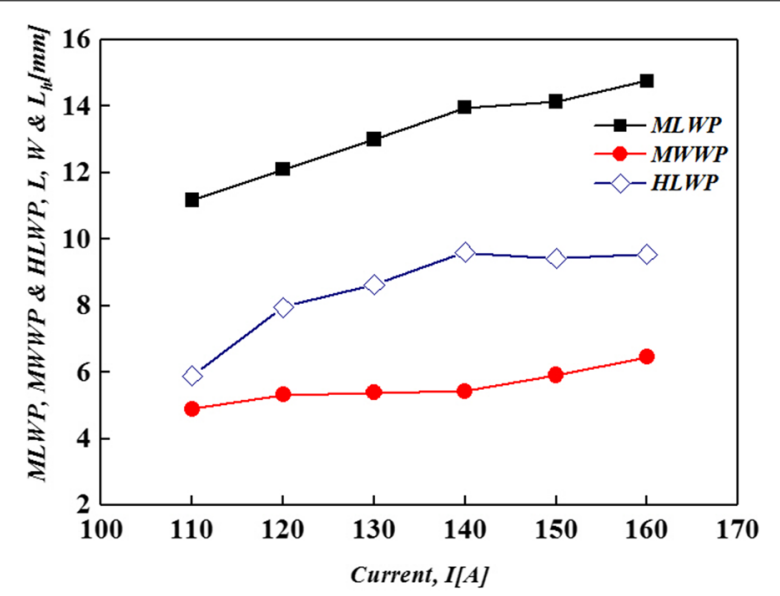

Figure 8 Variation trends of MLWP, MWWP and HLWP with the current

(the back-bead width is greater than $3 \mathrm{~mm}$ ), that the penetration is good at speeds of $20 \mathrm{~cm} / \mathrm{min}, 25 \mathrm{~cm} / \mathrm{min}$ and $30 \mathrm{~cm} / \mathrm{min}$, and that incomplete penetration occurs

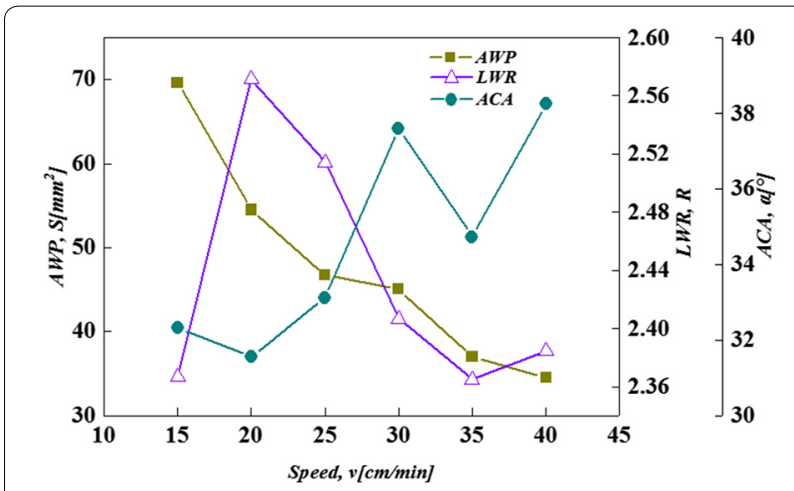

Figure 10 Variation trends of AWP, LWR and ACA with the speed

when the welding speed is set to $35 \mathrm{~cm} / \mathrm{min}$ or $40 \mathrm{~cm} /$ min (the back-bead width is less than $2 \mathrm{~mm}$ ). The variation in the geometry parameters with the welding speed is shown in Figure 10.

Figure 10 shows that with the increase in the welding speed, the AWP decreases; the LWR first increases and then decreases with a maximum value at the $20 \mathrm{~cm} / \mathrm{min}$ welding speed; and the minimum value of the ACA also appears at the $20 \mathrm{~cm} / \mathrm{min}$ welding speed. The penetration is in good condition when the value of AWP is in a certain range with the LWR close to the maximum and the ACA close to the minimum.

As the welding speed increases, the time within which the arc acts on the groove per unit length becomes shorter, and the welding heat input decreases, which leads to a decrease in the AWP. Meanwhile, the geometry parameters MWWP $(W)$, MLWP $(L)$ and HLWP $\left(L_{\mathrm{h}}\right)$ all decrease, but each parameter has a different descending gradient, as shown in Figure 11, which leads to the changes in the LWR and ACA with the speed shown in Figure 10.

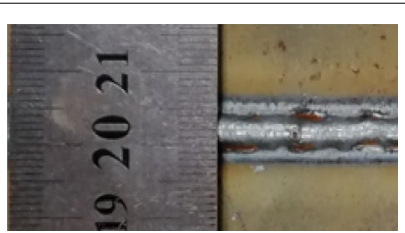

(a) $v=15 \mathrm{~cm} / \mathrm{min}$

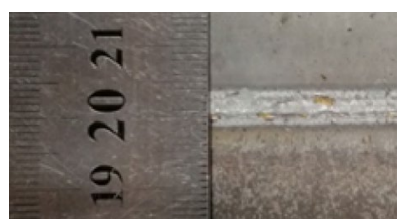

(d) $v=30 \mathrm{~cm} / \mathrm{min}$

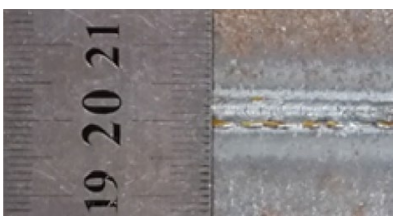

(b) $v=20 \mathrm{~cm} / \mathrm{min}$

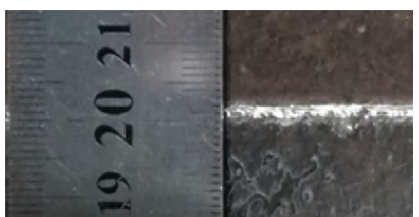

(e) $v=35 \mathrm{~cm} / \mathrm{min}$

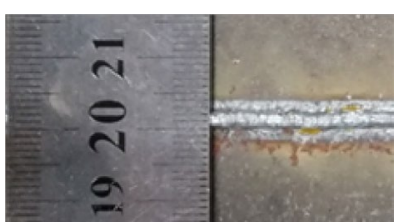

(c) $v=25 \mathrm{~cm} / \mathrm{min}$

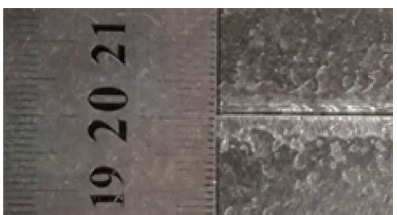

(f) $v=40 \mathrm{~cm} / \mathrm{min}$

Figure 9 Back of welds at different speeds 


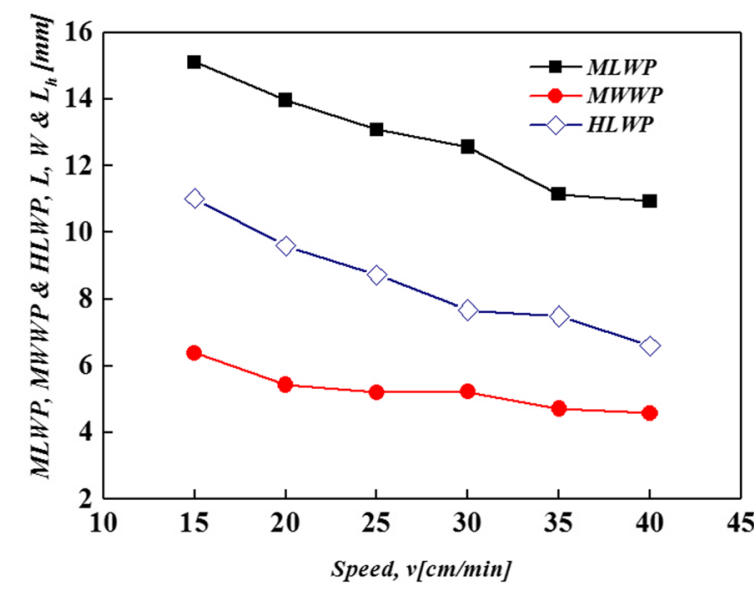

Figure 11 Variation trends of MLWP, MWWP and HLWP with the speed

It can be deduced from the above test data that complete penetration of the weld corresponds to a certain range of AWP values. Furthermore, referring to the values of the LWR and ACA is necessary to determine the penetration state more accurately.

\section{Estimation of Penetration from Weld Pool Geometry Parameters}

The above test results show that the AWP, MLWP and MWWP increase monotonically with the welding current and decrease monotonically with the welding speed. Meanwhile, the back-bead width, which is used to characterize the penetration state, increases with the current and decreases with the speed gradually. Therefore, there may be a linear relationship between the penetration state and the three geometry parameters. Multivariable linear regression analysis is used to determine the relationship between the three geometry parameters and the penetration state. Multivariable linear regression is a statistical analysis method that studies the linear relationship between a dependent variable and multiple independent variables, and the basic purpose of this method is to estimate the dependent variable with the values of multiple independent variables. A multivariable linear regression model is established to determine the strength and significance of the influence of the AWP, MLWP and MWWP on the penetration state and to estimate the penetration.

\subsection{Establishment of a Multivariable Linear Regression Model and Statistical Tests}

The independent variables are the AWP, MLWP and MWWP, which are represented by $S, L$ and $W$, respectively, and the dependent variable is the back-bead width, represented by $B_{w}$. The multivariable linear regression model is as follows:

$$
\left\{\begin{array}{l}
B_{w}=\beta_{0}+\beta_{1} S+\beta_{2} L+\beta_{3} W+\varepsilon \\
\varepsilon \sim N\left(0, \sigma^{2}\right)
\end{array}\right.
$$

where $\varepsilon$ is an error term used to explain the part of a change in a dependent variable that cannot be completely explained by the independent variables, $\varepsilon$ is independent and identically distributed with zero mean. $\beta_{j}(j=0$, $1,2,3)$ is an undetermined parameter with an estimated value $\hat{\beta}_{j}$ calculated by the least-squares method using the experimental sample data. Then, a multivariable linear regression model for predicting penetration can be obtained:

$$
\hat{B}_{w}=\hat{\beta}_{0}+\hat{\beta}_{1} S+\hat{\beta}_{2} L+\hat{\beta}_{3} W
$$

where $\hat{\beta}_{0}$ is a constant term and $\hat{\beta}_{1}, \hat{\beta}_{2}$ and $\hat{\beta}_{3}$ are regression coefficients. $\hat{\beta}_{1}$ is a partial regression coefficient of $S$ on $B_{w}$, i.e., the effect of one unit addition of $S$ on $B_{w}$; similarly, $\hat{\beta}_{2}$ and $\hat{\beta}_{3}$ are the partial regression coefficients of $L$ and $W$ on $B_{w}$.

The model, Eq. (5), needs to be checked by a goodnessof-fit test ( $R$-square test), the regression equation significance test ( $F$ test) and the variable significance test $(t$ test). In the goodness-of-fit test, the adjusted coefficient of determination $\bar{R}^{2}$ is as follows:

$$
\bar{R}^{2}=1-\frac{R S S /(n-k-1)}{T S S /(n-1)},
$$

where $R S S=\sum\left(B_{w i}-\hat{B}_{w i}\right)^{2} \quad(R S S$, residual sum of squares), $B_{w \mathrm{i}}$ is the sample value of the dependent variable, $\hat{B}_{w i}$ is the linear regression value of the dependent variable, $T S S=\sum\left(B_{w i}-\bar{B}_{w}\right)^{2}(T S S$, total sum of squares), $\bar{B}_{w}$ is the sample mean of the dependent variable, $n$ is the number of samples, $k$ is the number of independent variables $(k=3), n-k-1$ is the degree of freedom of RSS, and $n-1$ is the degree of freedom of TSS. The value of $\bar{R}^{2}$ should be greater than 0.5 , and the closer it is to 1 , the better the fitting degree of the regression line to the sample values. The $F$ test is used to infer whether the linear relationship between the dependent variable and the independent variables is generally significant in the model, that is, whether the partial regression coefficients of $\hat{\beta}_{j}(j=1,2,3)$ in the model, Eq. (5), are significantly not 0 . The statistic $F$ is calculated as follows:

$$
F=\frac{E S S / k}{R S S /(n-k-1)}
$$

where $E S S=\sum\left(\hat{B}_{w i}-\bar{B}_{w}\right)^{2} \quad(E S S$, explained sum of squares). Given the significance level $\alpha$, if $F \geq F_{\alpha}$ ( $k$, $n-k-1)$ is satisfied, then the linear regression model is 
significant. Otherwise, the linear regression model is not significant.

The $F$ test can demonstrate that the overall linear relationship of the linear regression equation is significant, but cannot show that each independent variable has a significant influence on the dependent variable. Therefore, each independent variable must be subjected to a significance test to determine whether the independent variable is retained in the model, which is done by the $t$ test of the variable. The statistic $t$ is calculated as follows:

$$
t=\frac{\hat{\beta}_{j}-\beta_{j}}{S\left(\hat{\beta}_{j}\right)},
$$

where $S\left(\hat{\beta}_{j}\right)$ is the standard deviation of $\hat{\beta}_{j}$. For the hypothesis of each $\beta_{j} \neq 0(j=1,2,3)$, the significant probability Sig. $<0.05$ of the $t$ test indicates that a linear relationship of $S, L$ and $W$ with $B_{w}$ significantly accepts the hypothesis; otherwise, the hypothesis is rejected.

\subsection{Regression Equation between the Weld Pool Geometry Parameters and the Back-Bead Width}

Considering the close relationship between the backbead width and the penetration state, the back-bead width is used to quantify the penetration. The method for determination of the back-bead width corresponding to each weld pool image was as follows: The image of the back side of weld pool was captured with the camera below the workpiece, which was synchronized with the camera above the workpiece for image acquisition of the weld pool surface. The information of the back-bead width was extracted by the image processing algorithm (see Figure 3) and then converted to the physical length by the camera calibration.

First, the regression equation between the geometry parameters and the back-bead width was established under the condition that the welding current was adjusted from $110 \mathrm{~A}$ to $160 \mathrm{~A}$. The sample data (the AWP, MLWP, MWWP and back-bead width) under each set of welding parameters were no less than 50 groups. The sample data were handled by the least-squares fitting and the result obtained is shown in Table 2 . The adjusted $R$ squared is 0.767 , which suggests that the regression equation has a high goodness of fit. The $F$ is 583.655, which is much larger than the $F_{\alpha}(3, m-3-1)$ value of 2.622 when the sample number $m$ is 532 at a significance level $\alpha=0.05$. That is, the linear relationship of the established multivariable regression model is significant at the $95 \%$ level. However, for the hypothesis that the 3 regression coefficients are not equal to zero, the MWWP's significance probability Sig. $>0.05$ in the $t$ test indicates that the linear relationship of the MWWP to the back-bead width of the weld pool does not accept the hypothesis significantly when the current changes. Therefore, only the AWP and MLWP were taken as the independent variables, and the corresponding relationship between them and the back-bead width was analysed. The result is shown in Table 3.

The standardized coefficients (Beta) in Table 3 are the regression coefficients calculated after the sample data are standardized (the difference between each sample and the mean is divided by the variance), which negates the influence of dimensions. According to the standardized coefficients, the AWP is the dominant factor in the

Table 2 Partial regression coefficients at different currents

\begin{tabular}{|c|c|c|c|c|c|c|c|}
\hline \multirow[t]{2}{*}{ Model } & \multicolumn{2}{|c|}{ Unstandardized coefficients } & \multirow{2}{*}{$\begin{array}{l}\text { Standardized } \\
\text { coefficients } \\
\text { Beta }\end{array}$} & \multirow[t]{2}{*}{$t$} & \multirow[t]{2}{*}{ Sig. } & \multirow[t]{2}{*}{ Adjusted $R$ squared } & \multirow[t]{2}{*}{$F$} \\
\hline & $\widehat{\boldsymbol{\beta}}$ & Std. error & & & & & \\
\hline (Constant) & -1.832 & 0.371 & & -4.944 & 0.000 & 0.767 & 583.655 \\
\hline AWP & 0.096 & 0.007 & 0.932 & 12.937 & 0.000 & & \\
\hline MLWP & -0.086 & 0.035 & -0.124 & -2.474 & 0.014 & & \\
\hline MWWP & 0.103 & 0.084 & 0.06 & 1.233 & 0.218 & & \\
\hline
\end{tabular}

Table 3 Partial regression coefficients without the MWWP at different currents

\begin{tabular}{|c|c|c|c|c|c|c|c|}
\hline \multirow[t]{2}{*}{ Model } & \multicolumn{2}{|c|}{ Unstandardized coefficients } & \multirow{2}{*}{$\begin{array}{l}\text { Standardized } \\
\text { coefficients } \\
\text { Beta }\end{array}$} & \multirow[t]{2}{*}{$t$} & \multirow[t]{2}{*}{ Sig. } & \multirow[t]{2}{*}{ Adjusted $R$ squared } & \multirow[t]{2}{*}{$F$} \\
\hline & $\widehat{\beta}$ & Std. error & & & & & \\
\hline (Constant) & -1.486 & 0.242 & & -6.135 & 0.000 & 0.767 & 873.864 \\
\hline AWP & 0.103 & 0.005 & 0.997 & 20.418 & 0.000 & & \\
\hline MLWP & -0.095 & 0.034 & -0.136 & -2.792 & 0.005 & & \\
\hline
\end{tabular}


linear relationship between the geometry parameters and the back-bead width, and the MLWP plays an auxiliary role.

As shown in Table 3, the regression equation between the weld pool geometry parameters and the back-bead width at different welding currents is

$$
\hat{B}_{w}=-1.486+0.103 S-0.095 L .
$$

Eq. (9) shows the coupling relationship between the geometry parameters and the back-bead width.

Similarly, multivariable linear regression analysis was used to analyse the relationship between the AWP, MLWP, and MWWP and the back-bead width with the increase in welding speed. Since the MWWP's significance probability Sig. (equal to 0.259 ) was greater than 0.05 in the $t$ test, the MWWP was removed from the independent variables and the relationship between the AWP, MLWP and the back-bead width was analysed. As shown in Table 4, the regression equation is

$$
\hat{B}_{w}=0.491+0.068 S-0.104 L \text {. }
$$

According to the standardized coefficients in Table 4, the AWP plays a dominant role in the linear relationship with back-bead width and the MLWP plays an auxiliary role.

\subsection{Verification Tests of Backing Welding}

To determine the reliability of regression equations Eq. (9) and Eq. (10), the above equations were verified by backing welding tests. The welding parameters for Eq. (9) verification were as follows: the welding current was varied from $110 \mathrm{~A}$ to $160 \mathrm{~A}$ with a step size of $10 \mathrm{~A}$, the welding speed was $20 \mathrm{~cm} / \mathrm{min}$, the workpiece groove angle was $60^{\circ}$, the welding wire diameter was $1.2 \mathrm{~mm}$, and the root opening was $1.6 \mathrm{~mm}$. The backing welding tests were carried out, the images of the surface and back side of the weld pool were captured synchronously, and the geometry parameters of the weld pool were extracted and substituted into Eq. (9) to estimate the back-bead width. The actual back-bead width was determined based on the back-side images of the weld pool. The mean values of the estimated back-bead width $\left(\hat{B}_{w}\right)$ and actual back-bead width $\left(B_{w}\right)$ at different currents are shown in Table 5.

As seen from Table 5, the back-bead width estimated by Eq. (9) agrees well with the actual back-bead width with the increase in the current. The penetration is in good condition under the currents of $130 \mathrm{~A}$ and $140 \mathrm{~A}$, and the estimated back-bead width is in the same range from $2 \mathrm{~mm}$ to $3 \mathrm{~mm}$ as the actual back-bead width with a small deviation. This result indicates that the relationship between the weld pool geometry parameters and the back-bead width determined by Eq. (9) is reliable.

The welding parameters for Eq. (10) verification were as follows: the welding speed was varied from $15 \mathrm{~cm} /$ min to $40 \mathrm{~cm} / \mathrm{min}$ with a step size of $5 \mathrm{~cm} / \mathrm{min}$, the welding current was $140 \mathrm{~A}$, the workpiece groove angle was $60^{\circ}$, the welding wire diameter was $1.2 \mathrm{~mm}$, and the groove gap was $1.6 \mathrm{~mm}$. The mean values of the backbead width estimated by Eq. (10) $\left(\hat{B}_{w}\right)$ and the actual back-bead width $\left(B_{w}\right)$ determined based on the backside images of the weld pool are shown in Table 6.

In Table 6, the estimated back-bead widths are essentially consistent with the actual back-bead widths, and the estimated back-bead width corresponding to penetration in good condition is in the $2 \mathrm{~mm}$ to $3 \mathrm{~mm}$ range at the speeds of $20 \mathrm{~cm} / \mathrm{min}, 25 \mathrm{~cm} / \mathrm{min}$ and $30 \mathrm{~cm} /$ min, which is the same as the actual back-bead width.

\begin{tabular}{|c|c|c|c|c|c|c|c|}
\hline \multirow[t]{2}{*}{ Model } & \multicolumn{2}{|c|}{ Unstandardized coefficients } & \multirow{2}{*}{$\begin{array}{l}\text { Standardized } \\
\text { coefficients } \\
\text { Beta }\end{array}$} & \multirow[t]{2}{*}{$t$} & \multirow[t]{2}{*}{ Sig. } & \multirow{2}{*}{$\begin{array}{l}\text { Adjusted } R \\
\text { squared }\end{array}$} & \multirow[t]{2}{*}{$F$} \\
\hline & $\widehat{\boldsymbol{\beta}}$ & Std. error & & & & & \\
\hline (Constant) & 0.491 & 0.245 & & 2.005 & 0.046 & 0.765 & 744 \\
\hline AWP & 0.068 & 0.005 & 1.079 & 14.869 & 0.000 & & \\
\hline MLWP & -0.104 & 0.035 & -0.217 & -2.991 & 0.003 & & \\
\hline
\end{tabular}

Table 4 Partial regression coefficients at different speeds

\begin{tabular}{|c|c|c|c|c|c|c|}
\hline Parameter & Value & & & & & \\
\hline Current I(A) & 110 & 120 & 130 & 140 & 150 & 160 \\
\hline Estimated back-bead width $\hat{B}_{W}(\mathrm{~mm})$ & 1.58 & 1.9 & 2.28 & 2.86 & 3.22 & 3.8 \\
\hline Actual back-bead width $B_{w}(\mathrm{~mm})$ & 1.64 & 1.85 & 2.17 & 2.67 & 3.16 & 4.13 \\
\hline
\end{tabular}

Table 5 Estimated and actual mean values of the back-bead width at different currents 
Table 6 Estimated and actual mean values of the back-bead width at different speeds

\begin{tabular}{|c|c|c|c|c|c|c|}
\hline Parameter & Value & & & & & \\
\hline Speed $v(\mathrm{~cm} / \mathrm{min})$ & 15 & 20 & 25 & 30 & 35 & 40 \\
\hline Estimated back-bead width $\hat{B}_{W}(\mathrm{~mm})$ & 3.72 & 2.8 & 2.32 & 2.26 & 1.81 & 1.65 \\
\hline Actual back-bead width $B_{\mathrm{w}}(\mathrm{mm})$ & 3.86 & 2.67 & 2.36 & 2.14 & 1.86 & 1.62 \\
\hline
\end{tabular}

Therefore, the corresponding relationship between the geometry parameters and the back-bead width determined by Eq. (10) is reasonable.

The above linear regression analysis and experimental verification show that the linear relationship between the weld pool geometry parameters and the back-bead width is feasible when the welding current or welding speed changes, that the AWP plays a leading role in the relationship with the back-bead width, and the MLWP plays an auxiliary role. The partial regression coefficients and constant in Eq. (9) are different from those in Eq. (10) because the change in heat input caused by variation in welding current is different from that caused by variation in welding speed. Different changes in heat input lead to distinctions in the variation trends of the weld pool geometry parameters and back-bead width. When the welding current and speed change simultaneously, the coupling effects of two welding parameters in the welding process will lead to the nonmonotonic variation trends of the AWP, MLWP and back-bead width, which does not meet the prerequisite of multivariable linear regression analysis. Therefore, the penetration estimation can not be achieved by combining the above two regression equations (Eq. (9) and Eq. (10)) into an equation in the case of simultaneous changes in the welding current and speed.

\section{Conclusions}

(1) With the increase in the welding current, the AWP, MLWP and MWWP increase monotonically, and the distributions of the LWR and ACA have inflection points; with the increase in the welding speed, the AWP, MLWP and MWWP decrease monotonically and the inflection points also appear in the distributions of LWR and ACA. When the AWP of the weld pool is within a certain range and the values of LWR and ACA are close to their maximum and minimum respectively, the penetration is in good condition.

(2) Multivariable linear regression equations are established to determine the corresponding relationship between the geometry parameters AWP, MLWP and the back-bead width when the welding current or welding speed changes. In the relationship, the AWP plays a leading role, and the MLWP plays an auxiliary role. The study provides basic data for the automation of backing welding with visual sensing.

\section{Abbreviations}

GMA: gas metal arc; AWP: area of the weld pool; MWWP: maximum width of the weld pool; MLWP: maximum length of the weld pool; HLWP: half-length of the weld pool; LWR: length-width ratio of the weld pool; ACA: advancing contact angle of the weld pool.

\section{Authors' Contributions}

JFH was in charge of the whole trial and wrote the manuscript; LX assisted with the establishment of the welding test platform and trial data analyses; JQH assisted with the establishment of the image acquisition system and related tests; $Y Z$ assisted with the GMA backing welding tests; KM assisted with the image acquisition and backing welding tests. All authors read and approved the final manuscript.

\section{Authors' Information}

Junfen Huang, born in 1975, is currently a teacher at Opto-Mechatronic Equipment Technology Beijing Area Major Laboratory, Beijing Institute of Petrochemical Technology, China. She received her PhD degree from Beijing University of

Technology, China, in 2005. Her research interests include automation welding technology and underwater welding.

Long Xue, born in 1966, is currently a professor at Opto-Mechatronic Equipment Technology Beijing Area Major Laboratory, Beijing Institute of Petrochemical Technology, China. He received his PhD degree from China University of Petroleum, China, in 2014. His research interests include man-machine system, welding robotics and ocean engineering.

Jiqiang Huang, born in 1971, is currently an associate professor at OptoMechatronic Equipment Technology Beijing Area Major Laboratory, Beijing Institute of Petrochemical Technology, China. He received his PhD degree from Beijing University of Technology, China, in 2004. His research interests include automation welding technology and underwater welding.

Yong Zou, born in 1976, is currently an associate professor at OptoMechatronic Equipment Technology Beijing Area Major Laboratory, Beijing Institute of Petrochemical Technology, China. He received his PhD degree from Beihang University, China, in 2016. His research interest is automation welding technology.

Ke Ma, born in 1993, is currently a master candidate at Opto-Mechatronic Equipment Technology Beijing Area Major Laboratory, Beijing Institute of Petrochemical Technology, China. His research interest is automation welding technology.

\section{Competing Interests}

The authors declare that they have no competing interests.

\section{Funding}

Supported by National Natural Science Foundation of China (Grant No.

51505035), Key Project of Science and Technology Plan of Beijing Municipal

Education Commission of China (Grant No. KZ201810017022), National Key 
R\&D Program of China (Grant No. 2017YFB1303300) and National Science and Technology Major Project of China (Grant No. 2018ZX04044001-009).

Received: 15 July 2018 Accepted: 22 May 2019

Published online: 18 June 2019

\section{References}

[1] Y Lei, X B Yuan, X N Sun. Application situation and prospect of automatic welding technology faced on pressure vessel. Pressure Vessel Technology, 2004, 21(10): 35-40. (in Chinese)

[2] G Q Hou, G F Liao, R Ma, et al. Research on improving the efficiency and welding quality of welding robot for construction machinery structure. Journal of Shanghai Jiao Tong University, 2016, 50(Sup.): 40-43. (in Chinese)

[3] G J Li, C HWu, B D Xu, et al. Ship curved plate column welding automation. Marine Technology, 2017, (2): 68-72. (in Chinese)

[4] L Xue, J M Wu, J F Huang, et al. Welding polarity effects on weld spatters and bead geometry of hyperbaric dry GMAW. Chinese Journal of Mechanical Engineering, 2016, 29(2): 351-356.

[5] Y Z Rong, R P Liu, Y H Wei. Welding database and expert system for aviation. Aeronautical Manufacturing Technology, 2017, (12): 43-47. (in Chinese)

[6] L Xue, Y Zou, J Q Huang, et al. Constant speed control for complex crosssection welding using robot based on angle. Chinese Journal of Mechanical Engineering, 2014, 27(2): 260-268.

[7] J F Yue, L Y Li, F L Fan, et al. Welding pool adaptive vision detection for arc welding robot gas metal arc welding. Journal of Mechanical Engineering, 2008, 44(4): 206-210. (in Chinese)

[8] Y Zou, L P Jiang, Y H Li, et al. Welding deviation detection algorithm based on extremum of molten pool image. Chinese Journal of Mechanical Engineering, 2016, 29(1): 74-83.

[9] J Q Huang, L Xue, J F Huang, et al. Arc behavior and joints performance of CMT welding process in hyperbaric atmosphere. Acta Metallurgica Sinica, 2016, 52(1): 93-99. (in Chinese)

[10] Y K Liu, Y M Zhang. Supervised learning of human welder behaviors for intelligent robotic welding. IEEE Transactions on Automation Science and Engineering, 2017, 14(3): 1532-1541.

[11] A S Baskoro, R Tandian, Haikal, et al. Automatic tungsten inert gas (TIG) welding using machine vision and neural network on material SS304. Proceedings of International Conference on Advanced Computer Science and Information Systems, East Java, Indonesia, October 15-16, 2016: 427-432.

[12] U Reisgen, P Lozano, S Mann, et al. Process control of gas metal arc welding processes by optical weld pool observation with combined quality models. Proceedings of IEEE International Conference on Automation Science and Engineering, Gothenburg, Sweden, Aug 24-28, 2015: 407-410.

[13] J S Chen, J Chen, Z L Feng, et al. Dynamic evolution of the weld pool reflection during weld penetration development. Proceedings of IEEE International Conference on Advanced Intelligent Mechatronics (AIM), Banff, Alberta, Canada, July 12-15, 2016: 548-553.

[14] T F Comas, C L Diao, J L Ding, et al. A passive imaging system for geometry measurement for the plasma arc welding process. IEEE Transactions on Industrial Electronics, 2017, 64(9): 7201-7209.
[15] R Kovacevic, Y M Zhang. Real-time image processing for monitoring of free weld pool surface. Journal of Manufacturing Science and Engineering, 1997, 119(5): 161-169.

[16] Y K Liu, Y M Zhang. Dynamic control of 3D weld pool surface based on human response model. Proceedings of 19th World Congress of the International Federation of Automatic Control, Cape Town, South Africa, August 24-29, 2014: 10640-10645.

[17] H Song, Y M Zhang. Error analysis of a three-dimensional GTA weld pool surface measurement system. Welding Journal, 2009, 88(7s): 141-148.

[18] W J Zhang, XW Wang, Y M Zhang. Analytical real-time measurement of a three-dimensional weld pool surface. Measurement Science and Technology, 2013, 24(11): 5011-5028.

[19] G Zhang, Y Shi, C K Li, et al. Measurement of characteristic parameters of three dimensional weld pool surface in Tungsten Inert Gas arc welding based on laser-vision. Journal of Shanghai Jiao Tong University, 2015, 49(3): 301-305. (in Chinese)

[20] Y K Liu, W J Zhang, Y M Zhang. Estimation of weld joint penetration under varying GTA pools. Welding Journal, 2013, 92(11): 313s-321s.

[21] Y K Liu, Y M Zhang. Model-based predictive control of weld penetration in Gas Tungsten Arc Welding. IEEE Transactions on Control Systems Technology, 2014, 22(3): 955-966.

[22] F Gao, M L Lu, B L Xu, et al. Multi region segmentation algorithm based on edge preserving for molten pool image. Proceedings of International Conference on Control, Automation and Information Sciences, Ansan, Korea, October 27-29, 2016: 210-214.

[23] C J Fan. Weld pool characters extraction visual sensing and intelligent control during varied gap aluminum alloy pulsed GTAW process. Shanghai: Shanghai Jiao Tong University, 2008. (in Chinese)

[24] HY Shen, H B Chen, T Lin, et al. Passive visual technology in aluminum alloy welding. Journal of Shanghai Jiao Tong University, 2015, 49(3): 341-343. (in Chinese)

[25] D M Wang, J Q Gao, C S Wu, et al. Vision-based detection of weld pool in short-circuit gas metal arc welding. Transactions of The China Welding Institution, 2008, 29(10): 85-88. (in Chinese)

[26] J Q Gao, C S Wu. Vision-based measuring of weld pool geometry in TIG welding. Acta Metallurgica Sinica, 2000, 36(12): 1284-1288. (in Chinese)

[27] J Liu, Z Fan, S I Olsen, et al. A real-time passive vision system for robotic arc welding. Proceedings of the IEEE International Conference on Automation Science and Engineering, Gothenburg, Sweden, 2015: 389-394.

[28] A M Neill, J P H Steele. Modeling and simulation of three dimensional weld pool reconstruction by stereo vision. Proceedings of IEEE International Conference on Advanced Intelligent Mechatronics (AIM), Banff, Alberta, Canada, July 12-15, 2016: 542-547.

[29] J Wang, W Wang, S Chen. Inspection of welding pool height from shading in pulsed GTAW with wire filler. Industrial Robot: An International Journal, 2009, 36(3): 270-276.

[30] D B Zhao, J Q Yi, S B Chen, et al. Extraction of three-dimensional parameters for weld pool surface in pulsed GTAW with wire filler. Journal of Manufacturing Science and Engineering, 2003, 125(3): 493-503.

[31] L P Li, X Q Yang, FY Zhang, et al. Research on surface recover of aluminum alloy P-GTAW pool based on SFS. Robotic Welding, Intelligence and Automation, Lecture Notes in Electrical Engineering, 2011, 88: 307-314. 